\title{
Prospects for the Development of Blended Learning Practice in Russia in the Context of Digitalization of the Higher Education System
}

\author{
Dokukina E.V. \\ Leonov Moscow Region University of Technology, \\ Korolev, Russia \\ Daneykin Y.V. \\ Yaroslav-the-Wise Novgorod State University, \\ Veliky Novgorod, Russia, \\ Yury.Daneykin@novsu.ru
}

\author{
Salmanova I.P. \\ Leonov Moscow Region University of Technology, \\ Korolev, Russia
}

\begin{abstract}
The modern socio-economic system is developing under the influence of the digitalization trend, which covers many areas o2f activity in Russia. Digitalization has a significant impact on the higher education system. One of the most promising approaches in this area is blended learning. This article discusses the main content elements of the blended learning paradigm, prospects, and problems of implementing blended learning technologies in Russia.
\end{abstract}

Keywords-blended learning, digitalization of education, innovation and education

\section{INTRODUCTION}

Modern education in the world and in Russia is developing in the context of digitalization, when new digital technologies become the basis for the competitiveness of organizations, including higher educational institutions.

In particular, the President of the Russian Federation V.V. Putin stated the need to introduce digital technologies into education processes, noting that the development of online education is extremely important and will allow the country to improve the quality of human resources significantly [1].

One of the most promising approaches in this area is blended learning. This approach is being actively implemented in Western universities and in several Russian universities. Even though this approach has already proven itself as more effective compared to the traditional approach to learning, there are a few difficulties associated with the practical implementation of blended learning.

This article will consider the main content elements of the blended learning paradigm, prospects, and problems of implementing blended learning technologies in Russia.

\section{Digitalization OF THE EDUCATION SYSTEM}

The modern socio-economic system is developing under the influence of the digitalization trend, which covers many areas of activity in Russia [2]. Digitalization has a significant impact on the education system, while this relationship is observed not only in Russian education, but also in most countries of the world [3]. Next, we will consider the concept of digitalization and the features of the manifestation of this trend in the education system.

Researchers [4] understand digitalization as the process of spreading the practice of using digital technologies to form new models of doing business. Digital technologies play a key role in this process. The most important technologies are Internet technologies and mobile technologies.

Digitalization has a strong impact on social communication in society. Some researchers [5] describe the process of digitalization as a process of transforming the usual methods of interaction of people with each other. This transformation is about the use of digital technology instead of analog technology or live communication. This is reflected in the more active use of social networks for communication, e-mail, instant messengers and other digital communication channels. At the same time, the practice of using analog technologies (for example, phone calls, sending letters via mail) takes a smaller role in communications.

Digitalization processes are fully reflected in the education system. And although there are currently no digital universities in Russia, that is, universities that use digital technologies as the main ones for teaching higher education programs, digitalization is already having an impact on the higher education system in Russia, for example, at the Higher School 
of Economics and the Financial University of the Russian Federation.

R. Safuanov [6] highlights the following features of the impact of digitalization on the higher education system in Russia:

- lack of mass quality higher education. The researcher concludes that the current system of higher education in Russia does not provide high educational standards at the mass level (for example, a large proportion of parttime students). This, in turn, limits the potential for introducing innovative technologies, creating new knowledge;

- low flexibility of information systems due to the high share of state universities in the higher education market;

- spreading the practice of using a two-component information environment. This information environment includes open resources of international platforms in the field of education (in particular, Coursera, FutureLearn, edX) and internal developments.

These features largely determine the future prospects for the development of new approaches to education, including the paradigm of blended learning. Let's consider in more detail the provisions of this educational paradigm.

\section{THE PARADIGM OF MIXED LEARNING}

Blended learning is currently one of the most promising innovative approaches in higher education, and this approach is already applicable in modern universities.

A. Ashhin [7] understands a new approach to understanding the essence of the education process by the blended learning paradigm, this approach includes a set of online courses and offline courses, educational modules based on different value approaches to the content and methodology of educational programs.

The main postulate of this paradigm is the following setting: "How it works in practice". Thus, the blended learning approach is fundamentally different from the previous education received: "The way it should be". Consequently, the blended learning approach focuses on meeting the current needs of the labor market, a deeper study of current trends and characteristics in a particular area.

S. Klinina [8] gives a more applied definition of blended learning. She defines blended learning as an approach to learning that uses traditional teaching methods in conjunction with distance learning. Remote technologies include the following:

- educational information platforms, which include specialized databases, personal accounts of all participants in the educational process, functionality for personalized management of the student's learning path, an electronic library and other resources;

- a system of remote support for learning processes. This system contains all the necessary materials for the organization of blended learning and guidelines;

- using e-mail or the functionality of educational platforms to organize communication processes between participants in the educational process;

- $\quad$ services for organizing video lessons (webinars);

- mass open on-line courses.

Thus, a key feature of blended learning is the combination of personal interaction between teacher and students and online formats. In particular, this quality is considered in the work of A. Loginova [9].

Blended learning as a new paradigm has a significant impact on the fundamental foundations of the educational process. A. Ashin [10] identifies four areas in which fundamental changes occur when introducing blended learning technologies:

- studying time. With the introduction of blended learning technologies, the structure of educational programs changes in terms of training time. New programs do not contain restrictions on the time of the school day, as well as the time of the school year;

- place of training. The introduction of online technologies makes it possible to conduct classes in an online format, so teachers and students do not necessarily use the university building for teaching;

- educational trajectory. In the classical approach to teaching, the management of the educational trajectory belongs to the function of the teacher, but blended learning assumes that students can independently adapt the content of educational programs and the conditions for their implementation to suit their needs. Consequently, personalization of higher education occurs with the introduction of blended learning technologies;

- educational platform. The space in which the interaction of various participants in the educational process takes place is no longer limited to the audience. The teacher and students can interact in other formats and platforms.

Thus, each of these areas is substantially modified because of the introduction of blended learning technologies. Consequently, the flexibility of the educational process management system plays a fundamentally important role. University managers must be prepared for the risks associated with the introduction of innovative technologies.

O. Asadchikh [11] identifies six models of blended learning (Fig. 1):

- face-to-face driver. This model assumes that teachers and students study the basic part of the material in terms of theory, while there is a parallel use of electronic resources. The practical part of the material is studied online. We can classify this model as one of the most traditional blended learning models;

- flipped classroom. This model assumes that students go through the theoretical part (that is, the lecture part) independently, using online resources. At the same time, students take the practical part of the course in an offline format together with the teacher;

- flexible communication. In this model, the teacher is available to students within the framework of offline consultations on the basis of a specific schedule, but 
students carry out most of the work on the basis of an information platform, that is, using online technologies;

- online laboratory. Within the framework of this model, the teacher performs the function of accompaniment for students who conduct laboratory work in computer classes. This model is also quite traditional compared to other models:

- $\quad$ self-blend. Within the framework of this model, students can independently manage the curriculum and their educational trajectory based on certain rules established by the university;

- online driver. This model assumes that almost all educational material will be studied by students remotely, and the interaction of the teacher and students in an offline format is carried out only during the periods of exams or consultations.

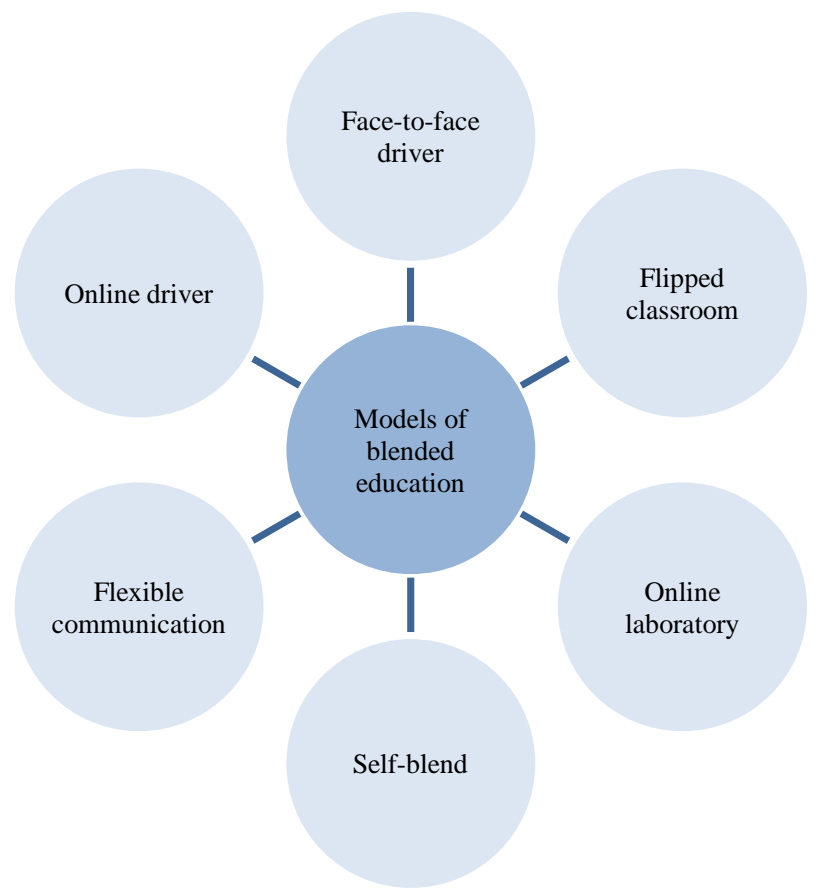

Fig. 1. Models of blended learning

Practical implementation of blended learning technologies.

The blended learning information environment has three components:

- technical environment, which includes computers (including laptops), mobile devices, Internet networks, etc.;

- educational resources. These resources include software, educational portals, digital libraries, video communication and audio communication technologies;

- process control. This component includes tools for managing the blended learning process, including email, personal account on the platform, social networks, cloud accounts, etc.

The effective integration of these components requires higher educational institutions to have a high flexibility of the management system, as well as the readiness of managers to make changes in the processes of personnel selection, organization of educational content, etc. Consequently, a large role is assigned to the strategy of the university. Making decisive changes in the educational process as part of the introduction of blended learning technologies requires a comprehensive action plan, clear goal setting and the desire of senior managers to implement a general development strategy.

\section{Prospects For The IMPLEMENTATION OF TECHNOLOGIES OF MIXED EDUCATION IN THE MODERN RUSSIAN SYSTEM OF HIGHER EDUCATION}

The prospects for the implementation of blended learning technologies in the modern Russian system of higher education are largely determined not only by the effectiveness of technology in solving educational problems, but by the readiness of the system itself for large-scale changes.

It is also important to note the high potential for the impact of the blended learning technologies themselves on various aspects of the educational process. These consequences must be controlled and quantified so that managers can minimize possible risks.

We can highlight the following perspectives of blended learning technologies for the higher education system in Russia (Fig. 2):

- development of processes of differentiation and specialization of approaches and programs of higher education. In this case, it is meant that the same program can use different approaches to learning, while the number of programs in the higher education market can also increase with the introduction of new technologies [12]. Also, it is important to note the process of strengthening specialization in higher education. New digital technologies enable a more personalized learning experience. Students can get a narrower education through more flexible technologies;

- sustainable changes in the content, structure, and organization of content in the field of education. The introduction of digitalization practice can also affect the organizational principles of the university, in particular, the principles of an individual approach [13], flexibility, creative and social skills are becoming more relevant;

- sustainable changes in the content, structure, and organization of content in the field of education. The introduction of digitalization practice can also affect the organizational principles of the university, in particular, the principles of an individual approach [13], flexibility, creative and social skills are becoming more relevant.

In our opinion, these areas will be most fully implemented in the medium term (4-5 years).

Among the most promising blended learning models for the Russian higher education system, we can single out a face-toface driver, flexible communication, and self-blend. These models are already partially used in a number of the most competitive universities in Russia (for example, the face-toface driver is common in several faculties of the Lomonosov Moscow State University), so the use of this experience can be productive for most universities in the country.

In addition, these models do not require large-scale investments since the basic tool in these models is the information platform. Such platforms are developed by large 
companies and provided as cloud services (for example, Moodle).

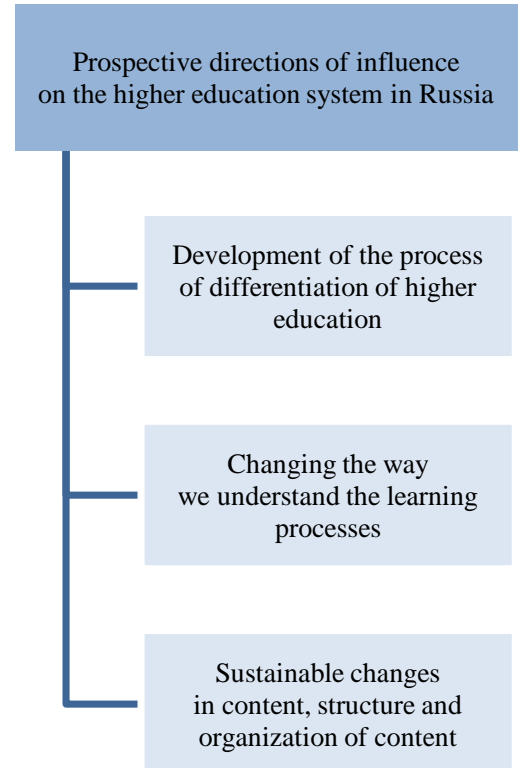

Fig. 2. Prospects for blended learning technologies for the higher education system in Russia

At the same time, several problems hinder the spread of the practice of introducing blended learning technologies in Russia. Among the most important problems, we can highlight the following:

- low level of flexibility of the management system (including strategic) in state universities of Russia [14];

- lack of financial resources during the economic crisis in the country and in the world economy as a whole;

- uneven distribution of economic resources among the regions of the Russian Federation and universities;

- a significant increase in the load on teachers. Deep study of materials, selection of high-quality electronic sources, processing of significant amounts of information, time-consuming for attractive design, etc. are required to implement a course with blended learning technologies at a high level of quality. A sharp increase in the workload on teachers can negatively affect the quality of courses;

- insufficiently high level of qualifications required for the high-quality implementation of blended learning technologies. Developers and educators must have a specific set of competencies and knowledge in the field of information technology. Currently, the practice of improving the qualifications of teachers in the field of blended learning is only being formed, but the further development of this practice can provide the higher education system in Russia with a serious foundation for the introduction of blended learning models;

- insufficient technical equipment. Most blended learning models pose major challenges to the technical base of most Russian universities. In particular, for the implementation of the inverted classroom model, special technical equipment is required for all classrooms and information educational space used for this. In addition, a rather serious problem is the provision of continuous and stable Internet access in the buildings of the university.

Government measures aimed at solving these problems and minimizing the consequences of these problems can significantly increase the prospects for the development of blended learning in the higher education system in Russia.

\section{V.CONCLUSION}

Blended learning is one of the most promising innovative approaches in higher education. Researchers understand the blended learning paradigm as a new approach to understanding the essence of the education process. A key feature of blended learning is the combination of personal interaction between teacher and students and online formats.

We have identified the following perspectives of blended learning technologies for the higher education system in Russia: the development of processes of differentiation and specialization of approaches and programs of higher education, sustainable changes in the content, structure and organization of content in the field of education and a change in the ways of understanding the learning processes themselves.

We came to the conclusion that the spread of the practice of introducing blended learning technologies in Russia is hindered by a number of problems, including a low level of flexibility of the management system, a lack of financial resources during the economic crisis, a significant increase in the workload on teachers, an insufficiently high level of qualifications and insufficient technical equipment. Among the most promising blended learning models for the Russian higher education system, we can single out the face-to-face driver, flexible communication, and self-blend.

\section{References}

[1] Presidential Address to the Federal Assembly March 1, 2018. (In Russ.).

[2] V.G. Khalin et al., Digitalization And Its Impact On The Russian Economy And Society: Advantages, Challenges, Threats And Risks, Administrative Consulting, 2018.

[3] O.N. Machekhina, "Digitalization Of Education As A Trend Of Its Modernization And Reforming", Revista Espacios, 2017, vol. 38(40)

[4] J. Gray, and B. Rumpe, "Models for Digitalization", Soft \& System Modeling, 2015, vol. 14(4), pp. 1319-1320.

[5] J.S. Brennen, D. and Kreiss, Digitalization, The international encyclopedia of communication theory and philosophy, 2016, pp. 1-11.

[6] R.M. Safuanov, M.Yu. Lehmus, and E.A. Kolganov, "Digitalization of the Education System", Bulletin of USPTU, Science, education, economics. Series: Economics, 2019, vol. 2(28).

[7] A.A. Ashin, and E.P. Potapova, "On the Classification of the Concepts of the Blended Learning Paradigm", Bulletin of the Novgorod branch of the RANEPA, 2017, vol. 6(2), pp. 128-133.

[8] S.D. Kalinina, "Conditions for the Effective Use of Webinars in the Educational Process of the University", Humanities and education, 2015, vol. 3(23), pp. 37-42.

[9] A.A. Ashin, and E.P. Potapova, "On the Classification of the Concepts of the Blended Learning Paradigm", Bulletin of the Novgorod branch of the RANEPA, 2017, vol. 6(2), pp. 128-133.

[10] A.V. Loginova, "Blended Learning: Benefits, Limitations and Concerns", Young Scientist, 2015, vol. 7.

[11] O. Asadchih, and T. Dybska, "The Experimental Testing of Blended Learning Methods of Oral Japanese Lanuage Teaching Aimed at Future Philologists", ScienceRise: Pedagogical Education, 2020, vol. 3(36), pp. 58-61. 
[12] I.V. Yanchenko, "Blended Learning at the University: From Theory to Practice", Modern problems of science and education, 2016, vol. 5, pp. 280-280.

[13] Yu.V. Daneykin, O.E. Kalpinskaya, and N.G. Fedotova, "Project Approach to the Implementation of an Individual Educational Trajectory in a Modern University", Higher education in Russia, 2020, vol. 8-9(29), pp. 104-116.

[14] B.A. Erznkyan, G.L. Bagiev, Yu.V. Daneikin, O.P. Ivanova, V.A. Trifonov, and V.A. Vladimirov, "Modernization of the Flagship University - Contribution to the Region Development", In the European Proceedings Of Social \& Behavioural Sciences, 2019. 